\title{
THE VALUE OF STAFF CONFERENCES IN STATE HOSPITALS.*
}

BY ELBERT M. SOMERS, M. D., First Assistant Physician, St. Lawrence State Hospital, Ogdensburg, N. Y.

Staff conferences, essentially medical in character, have been in operation in the various State hospitals of New York State since the year 1905 , as required by law.

The introduction and adoption of newer methods of clinical study, shortly before this period, clearly emphasized the need of more uniform and concerted action on the part of hospital staffs with reference to the study of the mental and physical condition of those admitted for care and treatment.

Previously, some of the hospitals had, for some time, held more or less regular meetings, but they were pre-eminently for administrative purposes.

Staff meetings, fortunately for all concerned, have now become medical clearing houses, and have been of value in proportion to the interest manifested by the individuals taking part in the work. Cases have become common property and experience consequently widened.

The former methods, whereby, largely through heresy, or on account of unusual interest, only a few came before the staff, have been corrected as far as possible.

There are obvious reasons why the entire staff should share in the results of every examination that has been made by another. Clinical work is better for having been scrutinized and passed upon in a formal way rather than casually brought to notice.

The facts of the history, the mental and physical findings and the patient are presented. All are considered with the view of giving full value to the diagnostic points.

The impressions thus made are less likely to lose their force or fail to be of help in the study and observation of future cases. It is not to be forgotten that purely physical questions should receive their share of attention in relation to psychoses.

* Read at the sixty-fifth annual meeting of the American Medico-Psychological Association, Atlantic City, N. J., June I-4, 1909. 
Criticism under the proper conditions is also a valuable feature in bringing out points of interest that may have been overlooked. The best policy, as to the treatment of a case, is known to all. The impression gained by the patient, that the entire staff is interested in his behalf, aids materially in gaining the good will and confidence of the subject. The various services in institutions become less individualized and apart. They are rather made to contribute whatever may be of medical interest to the general fund, and those in charge draw their experiences from sources broader than formerly, for each member of the staff is continually assigned new cases for study and presentation.

A properly organized staff conference is a step forward in hospital organization, and when it is fully inaugurated there seems to be no good excuse for substituting the time thus spent for other methods of instruction.

Uniform methods of examination with definite times set apart for the mutual consideration, as far as possible, of medical questions, cannot be considered as impracticable, either because too much time may be required or because of fear that other matters of routine will be neglected. The arguments against this procedure can best be made only after a fair trial.

It is probably true that no State hospital staff is so busy that it cannot set apart some portion of time for conference upon strictly medical matters.

The sole object of this paper is to briefly point out some of the elements of value in staff conferences, based upon the assumption that all obstacles for their prosecution have been successfully removed. Therefore, one's description will be largely from personal experience in a hospital where daily conferences are the rule.

In organizing the medical program for such meetings, it should be the duty of the one in charge of the clinical department to assign cases to other members of the staff as soon as they are admitted, and so arrange the work that it be as equally divided as possible. This duty rather naturally falls to the first assistant physician, as he usually has general oversight of the recent admissions and of all clinical matters generally.

In institutions where the annual admissions are not over 400 , and the ratio of physicians to the general population is about one 
to 170 , all the cases can, upon entry, be fully examined and presented a sufficient number of times before their discharge if daily conferences are held. Many of the larger hospitals of this State, however, have admission services so active that even daily conferences could not properly dispose of all the cases. The practical advantages gained by the presentation of as many cases as possible, nevertheless, holds good.

In the selection of cases to be presented, enough material should be provided to completely occupy at least one hour.

It has been found feasible to present all cases under three different conditions. First, within five days after admission. Second, when the case is completely worked up, usually within six weeks. Third, before discharge.

The advantages of the first presentation are of some importance. In New York State there is a statutory regulation that requires the superintendents of hospitals to see all patients within five days after admission, and thereby this requirement is conveniently observed, as the superintendent is naturally the presiding officer during the clinical hour.

At this period, more attention is paid to the points of history than to making a diagnosis, and in addition, to primarily determine whether the patient is a proper subject for detention in the institution. Therefore, the attendant, whose trained duty it was to obtain from the relatives or otherwise as full a history as possible before bringing the patient to the hospital, is also required to be present before the staff in order that the errors of history may be corrected, doubtful points inquired into and fuller descriptions of certain events obtained. ${ }^{1}$ In this way, there is often gained additional information of value, the mental level of the relatives and home conditions are better understood, and the history, when recorded, is in better form.

This method of scrutiny of the attendant's report has its obvious advantages and tends to make him more accurate in his inquiries.

Those hospitals, which draw their patients from large rural

${ }^{1}$ The New York State hospitals send, upon notification, trained attendants to the homes of patients, for whom admission has been sought, to convey such patients to the hospital. 
sections, depend greatly upon the thoroughness of the attendant's account. The opportunities for personally interviewing the relatives are not as frequent as in compact city districts.

For the sake of a better understanding of the cases, carefully framed letters of inquiry to the relatives or to the family physician of the patient are sometimes necessary, should the attendant for one reason or another fail to gather satisfactory information.

At this presentation, it is not advisable to attempt to examine the patient to any extent, but rather to tactfully explain to him the reasons for his detention and generally to give him the impression, as far as possible, that full consideration will be given his condition. For this manifestation many patients are grateful and others are disposed to be more free in their attitude and conversation when the mental status is seriously sought by the examiner. It rarely does harm.

Incidentally, however, observations at this time are recorded as to the reactions of the patient since entry. The examiner briefly reports whatever points of interest he may have had time to obtain, particularly as to the physical condition, the immediate therapeutic indications and the more important mental features, such as the orientation, evidences of hallucinosis, the character of the productivity or any other features which can be readily demonstrated without taking too much time.

A brief, general survey of the patient, as soon as possible after admission, is of clinical advantage to all and enhances the subsequent impression gained when the case is again presented in a more complete form for diagnosis. Furthermore, this method leaves the records of those who suddenly die, or are removed, in better order. Some things of value may have been noted which would, otherwise, have been missed.

There are, in the course of admissions, some cases which can be properly worked up and disposed of, as far as the physical and mental conclusions are concerned, within the five days. These are principally cases of well-recognized deteriorations, such as the senile and epileptic, and occasionally cases of well-marked general paralysis. But the conclusions, however, should not be accepted until they are apparent to all, and it is not to be forgotten that in these cases interesting conditions subsequently 
arise for further study such as neurological or other organic manifestations.

Relatively few patients are in such condition that they cannot be presented before the staff. Those that cannot are so because of some serious physical disorder or, rarely, because of extreme sensitiveness, such a state as we might readily infer in the case of a refined woman, depressed and fatigued upon entry.

The second presentation of the case is made only after the examiner has, as fully as possible, completed his examination. Six weeks are sufficiently long in which to gather and put in typewritten order what is obtained. For the sake of clearness a summary of the findings is submitted rather than the whole case in order to cover in succinct and comprehensive form the principal features of the case. The complete examination can, at any time, be referred to whenever more detail is required concerning some particular point.

It seems not wise to defer longer in hopes of adding anything materially helpful for diagnostic purposes, even if inaccessibility is the stumbling block. There will be a small percentage of cases that cannot be satisfactorily classified even at a more remote period, but enforced postponements for this reason should not deter energetic and painstaking efforts to come to early and fairly sound conclusions in those cases in which the symptoms are demonstrable.

It would add nothing to the value of a case of general paralysis to wait for positive evidences of memory faults before giving the disease a diagnostic name. The exhibition would be of more interest before this stage. The habit of waiting too long before making a diagnosis robs the case of its freshness and interest for others. The salient points become historical rather than clinical and the examiner substitutes convenience for expediency.

It is decidedly more interesting for the staff to witness retardation rather than to take another's word for it. A manic case is more instructive when he can be readily shown to be so. The mood, attitude and manner of the hallucinated person mean more when observed early. A case should be shown when it is worth while if clinical material is to be the means of sharpening our knowledge and rendering us more resourceful. 
After the record is presented and the patient properly interviewed and dismissed, discussions are then in order. Herein rests much of the further value of a staff conference. The one who presented the case has been mindful of this when summarizing the record and arranging his diagnostic points. The contentions and arguments incident to such discussions should be pertinent and not allowed to become too miscellaneous or unprofitable.

In the main, the following questions are up for consideration, namely: What is your impression of the case? Do you agree in the conclusions that have been drawn? What features do you see that are unusual or that differ from those manifested in former cases of the same type? Have the therapeutic indications been met? What factors influence the prognosis?

In this way the case is not simply disposed of by merely giving it some diagnostic name. This characterization can be best reserved till the last. The more important consideration is whether we have understood the individual case, and of what use can it be in practical work.

A record of such a presentation should be made by the examiner covering the important features elicited from the patient and the opinions expressed by the various members of the staff. By this means, aid is given in the subsequent observation of the patient in whatever service he may be.

There are occasionally good reasons for again presenting the case to show some unusual mental or physical conditions that may have arisen or because of some obscurity regarding previous symptoms.

The final presentation of a patient is made when his discharge comes up for consideration. This usually takes but little time particularly if the case has recovered. Under any conditions it is well to know as far as possible the exact mental attitude of those who are to leave our charge. A brief review of the main points of the case, together with the course of psychosis, is submitted, and the welfare of the patient, as well as the interests of the community from which he came, are determined by what is found. If the patient is well, some profit accrues from learning under what circumstances and by what method he was able to 
readjust himself. What may constitute insight is a feature peculiar to each case.

Lastly, it seems advisable to set apart some portion of an hour during the week for the consideration of any autopsies that may have been held. The findings are considered in relation to the clinical notes. The extent of the continued observation and interest in the cases, which have been more or less disposed of, are hereby measured. The accuracy of the diagnosis of intercurrent physical disorders and of the terminal disease are here put to the test, and oversights become matters for explanation.

It is probable that in the past the necropsy has been put too much apart by itself, and has not been considered in close enough relationship to conditions found existing during life. Autopsy material manifestly belongs to the clinician. It is his case even after death and no autopsy should be conducted unless the examiner is there with the record of the case. Furthermore, the pathologist is thereby better guided in his immediate investigations.

In some such way, as briefly outlined, can the hour given to consultation be made profitable. It is this kind of schooling that will be likely to help the staff to keep pace with the present day requirements of practical psychiatry.

Matters of medical import are brought into better line with something definite in view, namely: Accuracy of observation, correction of wrong impressions and construction of permanent records, which contain more complete and orderly data for future help. In addition good opportunities exist for subjecting to practical test whatever may be found in general literature and mere book knowledge takes its proper level.

Daily conferences give the superintendent a greater personal knowledge of the general medical activity of his staff and he is in a better position to measure the value of each individual. 